\title{
Spontaneous breathing in patients with severe acute respiratory distress syndrome receiving prolonged extracorporeal membrane oxygenation
}

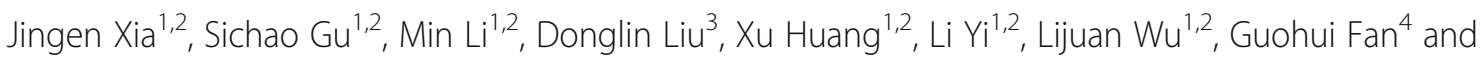
Qingyuan Zhan ${ }^{1,2^{*}}$

\begin{abstract}
Background: The use of extracorporeal membrane oxygenation (ECMO) in awake, spontaneously breathing and non-intubated patients (awake ECMO) may be a novel therapeutic strategy for severe acute respiratory distress syndrome (ARDS) patients. The purpose of this study is to assess the feasibility and safety of awake ECMO in severe ARDS patients receiving prolonged ECMO (> 14 days).

Methods: We describe our experience with 12 consecutive severe ARDS patients (age, $39.1 \pm 16.4$ years) supported with awake ECMO to wait for native lung recovery during prolonged ECMO treatment from July 2013 to January 2018. Outcomes are reported including the hospital mortality, ECMO-related complications and physiological data on weaning from invasive ventilation.

Results: The patients received median $26.0(15.5,64.8)$ days of total ECMO duration in the cohort. The longest ECMO support duration was 121 days. Awake ECMO and extubation was implemented after median 10.2(5.0, 42.9) days of ECMO. Awake ECMO was not associated with increased morbidity. The total invasive ventilation duration, lengths of stay in the ICU and hospital in the cohort were $14.0(12.0,37.3)$ days, $33.0(22.3,56.5)$ days and $46.5(27.3$, 84.8) days, respectively. The hospital mortality rate was $33.3 \%$ (4/12) in the cohort. Survivors had more stable respiratory rate and heart rate after extubation when compared to the non-survivors.
\end{abstract}

Conclusions: With carefully selected patients, awake ECMO is a feasible and safe strategy for severe pulmonary ARDS patients receiving prolonged ECMO support to wait for native lung recovery.

Keywords: Extracorporeal membrane oxygenation, Acute respiratory distress syndrome, Spontaneous breathing, Mechanical ventilation

\section{Background}

Extracorporeal membrane oxygenation (ECMO) is often used as a rescue therapy for patients with severe acute respiratory distress syndrome (ARDS) refractory to conventional invasive mechanical ventilation (IMV) [1]. Due to the novel development of ECMO-related technologies [2] and, in 2009, the global outbreak of a new H1N1

\footnotetext{
* Correspondence: zhanqycjfh@163.com

${ }^{1}$ National Clinical Research Center for Respiratory Diseases, Center for Respiratory Diseases, China-Japan Friendship Hospital, Beijing, China ${ }^{2}$ Department of Pulmonary and Critical Care Medicine, China-Japan Friendship Hospital, Beijing, China

Full list of author information is available at the end of the article
}

influenza virus [3], the number of cases of successful ECMO use for severe ARDS is growing yearly, but the overall mortality rate remains as high as 50-60\% [4-7].

"Awake" ECMO is a novel ECMO strategy that uses ECMO for awake, spontaneously breathing and nonintubated critically ill patients $[8,9]$. Recently, the application of awake ECMO in patients with chronic end-stage respiratory diseases awaiting lung transplantation [9-12] and chronic obstructive pulmonary disease [13-15] has increased, but its use in severe ARDS patients is rare [16-18]. Several recent clinical physiological studies [19-21] have shown that, in severe ARDS cases, ECMO alone may be able to replace

(c) The Author(s). 2019 Open Access This article is distributed under the terms of the Creative Commons Attribution 4.0 International License (http://creativecommons.org/licenses/by/4.0/), which permits unrestricted use, distribution, and reproduction in any medium, provided you give appropriate credit to the original author(s) and the source, provide a link to the Creative Commons license, and indicate if changes were made. The Creative Commons Public Domain Dedication waiver (http://creativecommons.org/publicdomain/zero/1.0/) applies to the data made available in this article, unless otherwise stated. 
IMV for regulating spontaneous breathing effort and minute ventilation by ECMO gas flow. Therefore, awake ECMO may be a potential novel strategy to replace invasive mechanical ventilation for severe ARDS patients without multiple organ dysfunction $[8,16]$.

The median duration of ECMO to treat acute respiratory failure is typically 7 to 10 days, however some patients may need longer time to wait for the recovery of native lung function [22, 23]. From Extracorporeal Life Support Organization registry [24], a total of 4488 respiratory failure patients treated with ECMO from 1986 to 2013 were collected, $22 \%$ of whom needed ECMO support for more than 14 days (prolonged ECMO), especially since 2008, the number of prolonged ECMO increased markedly. It is still unclear how to wean reasonably from prolonged ECMO in ARDS patients. If ECMO alone can supply adequate gas exchange at this time [19-21], awake ECMO strategy with early extubation in prolonged ECMO patients may reduce the complications associated with invasive positive pressure ventilation, such as barotrauma and VAP, even may improve the prognosis [1]. However, the decision of when to implement awake ECMO is in doubt. Therefore, we first present our experience with 12 ARDS patients treated with awake ECMO to wait for native lung recovery during prolonged ECMO treatment.

\section{Methods}

We retrospectively reviewed the prospectively constituted ECMO database of our 26-bed medical ICU to identify all severe ARDS patients supported with ECMO between July 2013 and January 2018. The screening criteria for awake ECMO patients in the cohort were as follows: (1) had a total ECMO duration of more than 14 days, (2) had endotracheal tube removal at least $48 \mathrm{~h}$ before the discontinuation of ECMO. This study was approved by the ethics committee of our center.

Patients were considered for ECMO if they had severe hypoxemia (e.g. the ratio of $\mathrm{PaO} 2$ to $\mathrm{FiO} 2$ less than 80 $\mathrm{mmHg}$ ) and uncompensated hypercapnia with academia $(\mathrm{pH}<7.15)$ despite the application of lung protective strategy with high PEEP $(12-20 \mathrm{cmH} 2 \mathrm{O})$ or recruitment maneuver. All the patients in the cohort were received venovenous ECMO (VV-ECMO) with the cannulation of the right or left internal jugular vein and right femoral vein.

Awake ECMO was considered when patients still needed high blood flow ECMO support after 7 to 10 days of ECMO treatment in our center. The final decision to implement awake ECMO was made by multidisciplinary ECMO team. The specific reference standard included the recovery of primary pulmonary disease with decreased pulmonary infiltration on chest $\mathrm{x}$-ray; clear consciousness; strong airway protection capability; no obvious airway secretions or airway inflammation upon fiberoptic bronchoscopy; stable hemodynamics; no arrhythmia; assisted ventilation mode with peak airway pressure $<20 \mathrm{cmH} 2 \mathrm{O}, \mathrm{PEEP}<10 \mathrm{cmH} 2 \mathrm{O}$ and $\mathrm{FiO} 2<0.5$; barotrauma or high risk of barotrauma (such as pulmonary bullae); high risk of VAP, as in the case of immunocompromised patients; ECMO running very well; stable coagulation and fibrinolysis system; no obvious signs of infection of vessel puncture site; and no signs of serious ECMO-related complications, such as major bleeding. The endotracheal intubation was immediately removed once awake ECMO was decided.

The ventilator mode before extubation was pressure support ventilation with positive end-expiratory pressure (PEEP) $7.0(2.8,8.0) \mathrm{cmH} 2 \mathrm{O}$, tidal volume (VT) 3.9 (3.3, 6.4) $\mathrm{ml} / \mathrm{kg}$, airway peak pressure $18.5(13.8,23.0)$ $\mathrm{cmH} 2 \mathrm{O}$, and respiratory rate $21.0(16.2,25.0) \mathrm{bpm}$. After extubation, the infusion of sedative and analgesic drugs was stopped. Low dose dexmedetomidine was given by $0.5 \sim 1 \mu \mathrm{g} / \mathrm{kg} / \mathrm{h}$ to maintain the Ramsay score $2 \sim 3$ points if the patient was agitated. Early mobilization during awake ECMO including active limb activities, sitting on the bed, standing at the bedside was gradually started with the help of intensivists, respiratory therapists, nurses and physical therapists. Besides, respiratory therapists also assisted such patients to practice breathing exercises, such as lung expansion (incentive spirometry), diaphragmatic breathing, directed cough, and airway flutter therapy.

The oxygen therapy modality during awake ECMO could be noninvasive positive pressure ventilation, high-flow nasal cannula, oxygen mask or nasal catheter, according to the patient's comfort. Awake ECMO treatment was considered failure if patients met the following criteria: severe dyspnea and respiratory rate more than $30 \mathrm{bpm}$ even maximal ECMO support; inability to clear airway secretion; increased pulmonary infiltration on chest $\mathrm{x}$-ray; inadequate gas exchange by ECMO alone; unstable hemodynamics. Once awake ECMO failed, the patients should be reintubated immediately. When native lung function appeared adequate to allow the patient to come off ECMO, we performed a trial off: the blood flow was kept constant, and the ECMO gas source was closed for $2-4 \mathrm{~h}$. When the respiratory rate was $<25 \mathrm{bpm}, \mathrm{PaCO} 2<50 \mathrm{mmHg}, \mathrm{PaO} 2>$ $60 \mathrm{mmHg}$ and hemodynamic stabilization on spontaneous breathing, the patients were ready for decannulation.

We collected demographic information and data related to ARDS etiology, comorbidity, and pre-ECMO baseline parameters, including Acute Physiology and Chronic Health Evaluation (APACHE) II score, ventilator settings, gas exchange, and the duration of IMV before ECMO. ECMO-related parameters during the ECMO run were also recorded as follows: total ECMO duration, blood flow, gas flow, ventilator settings and 
ECMO-related complications, including circuit complications (malfunction of any component of the circuit, clot and air in circuit), hemorrhage (gastrointestinal, surgical and pulmonary hemorrhage), ECMO-related infection (VAP, cannula infection and urinary tract infection), barotrauma, neurological complications, renal complications and cardiovascular complications. In addition, we documented the relevant ECMO, respiratory, circulation and routine laboratory test parameters at the onset of and after extubation. The main clinical outcome was hospital mortality, and secondary outcomes included the total duration of IMV and ECMO and the length of stay in the ICU and the hospital.

Data are presented as the mean (SD) or median (range) for continuous variables and as frequency and percentage for categorical variables. Continuous data (respiratory rate and heart rate) were compared between the two groups using Wilcoxon rank sum test. Changes in the measurement of respiratory rate and heart rate between survivor and non-survivor were analyzed using two-way repeated measures ANOVA. A $P$ value less than 0.05 level of significance was set. Analyses were performed using SPSS 23 (SPSS, Inc., Chicago, IL, USA).

\section{Results}

\section{Characteristics of the included patients}

A total of 80 patients underwent ECMO due to ARDS during the study period, of which $12(15 \%)$ severe ARDS patients needed prolonged ECMO support ( $>14$ days) and received awake ECMO (Table 1). Pneumonia was the most common cause of ARDS. The median $\mathrm{PaO} 2 /$ $\mathrm{FiO} 2$ ration before ECMO was $61.8(50.6,90.4) \mathrm{mmHg}$. The median time from invasive ventilation to ECMO was $3.2(1.0,4.7)$ days. Ventilator settings and gas exchange variables are shown in Table 2.

\section{Clinical implementation of awake ECMO}

In the cohort, patients were extubated after 10.2(5.0, 42.9) days of ECMO with higher ECMO blood flow [3.5 $(3.2,3.8) \mathrm{L} / \mathrm{min}]$ and gas flow $[4.3(3.0,7.6) \mathrm{L} / \mathrm{min}]$. Pulmonary infiltration on chest $\mathrm{x}$-ray was decreased significantly (Fig. 1). The choice of oxygen therapy modality for awake ECMO patients was as follows: 8 (66\%) patients received oxygen through a high-flow nasal cannula, 2 (17\%) patients received conventional oxygen therapy, and $2(17 \%)$ patients were treated with noninvasive positive pressure ventilation. The median duration of awake ECMO was $12.0(7.0,26.8)$ days.

After disconnection from invasive ventilation, the respiratory rate increased slightly during the first $24 \mathrm{~h}$ both for survivors and non-survivors. In the next 7 days after extubation, respiratory rate (time effect $P=0.018$, time $\times$ group effect $P=0.032$ ) and heart rate (time effect $P=$ 0.005 , time $\times$ group effect $P=0.001$ ) were more stable in survivors, however, these variables gradually increased in non-survivors. (Fig. 2).

\section{Outcomes}

The hospital mortality was $33.3 \%(4 / 12)$ in the cohort. Three patients (Patient 2, 4 and 6) were reintubated for refractory hypoxemia and severe dyspnea at the seventh, second and fifth days after extubation, and all died of septic shock and multiple organ failure due to the progression of the primary pulmonary disease. Patient 2 was extubated from invasive ventilation after 10 days of ECMO treatment. Due to the progressing of primary pneumonia

Table 1 Patient characteristics and outcomes

\begin{tabular}{|c|c|c|c|c|c|c|}
\hline Patient & Cause of ARDS & $\begin{array}{l}\text { Underlying } \\
\text { disease }\end{array}$ & $\begin{array}{l}\text { Pre-ECMO } \mathrm{PaO}_{2} / \mathrm{FiO}_{2} \\
(\mathrm{mmHg})\end{array}$ & $\begin{array}{l}\text { Pre-ECMO APACHE II } \\
\text { Score }\end{array}$ & $\begin{array}{l}\text { Pre-ECMO IMV duration } \\
\text { (Days) }\end{array}$ & Alive \\
\hline 1 & Pneumonia (Legionella) & Hypertension & 50.1 & 15 & 1.1 & Yes \\
\hline 2 & $\begin{array}{l}\text { Pneumonia (Streptococcus } \\
\text { pneumoniae) }\end{array}$ & None & 59.0 & 11 & 11.8 & No \\
\hline 3 & Pneumonia (H1N1) & None & 50.1 & 17 & 3.0 & Yes \\
\hline 4 & Pneumonia (H1N1) & AML & 94.7 & 17 & 3.5 & No \\
\hline 5 & Pneumonia (Pneumocystis carinii) & SLE & 52.0 & 23 & 1.0 & Yes \\
\hline 6 & Pneumonia (unidentified organism) & None & 96.0 & 15 & 0.04 & No \\
\hline 7 & Pneumonia (H7N9) & None & 35.2 & 24 & 0.4 & Yes \\
\hline 8 & Acute interstitial pneumonia & None & 60.6 & 17 & 3.9 & Yes \\
\hline 9 & Pneumonia (Aspergillus fumigatus) & Bronchiectasis & 63.0 & 17 & 4.8 & Yes \\
\hline 10 & Acute interstitial pneumonia & None & 77.5 & 13 & 1.0 & Yes \\
\hline 11 & Pneumonia (H1N1) & None & 108.0 & 10 & 4.3 & Yes \\
\hline 12 & Pneumonia (H1N1) & Hypertension & 65.0 & 24 & 7.0 & No \\
\hline
\end{tabular}

AML acute myelogenous leukemia; APACHE /l Acute Physiology and Chronic Health Evaluation II; IMV invasive mechanical ventilation; SLE systemic lupus erythematosus 
Table 2 Baseline characteristics and pre-extracorporeal membrane oxygenation ventilator settings and gas exchange variables

\begin{tabular}{ll}
\hline Characteristics & Awake ECMO $(n=12)$ \\
\hline Age (years) & $39.1 \pm 16.4$ \\
Female, $\mathrm{n}(\%)$ & $5(41.7 \%)$ \\
Body mass index $\left(\mathrm{kg} / \mathrm{m}^{2}\right)$ & $25.8 \pm 5.3$ \\
APACHE II score & $17.0(13.5,21.5)$ \\
Murray score & $3.4(2.8,3.8)$ \\
Duration of IMV(day) & $3.2(1.0,4.7)$ \\
Pre-ECMO variables & \\
VT (ml) & $390.0(216.5,440.5)$ \\
VT pbw (ml/kg) & $6.6(3.3,7.1)$ \\
Respiratory rate (bpm) & $30.0(25.0,31.0)$ \\
Pplat (cmH2O) & $31.0(24.0,32.5)$ \\
PEEP (cmH2O) & $14.0(8.5,16.5)$ \\
FiO2 & $1.0(1.0,1.0)$ \\
pH & $7.40(7.33,7.43)$ \\
PaCO2 (mmHg) & $46.2(42.9,52.0)$ \\
PaO2/FiO2 & $61.8(50.6,90.4)$ \\
Lac (mmol/L) & $1.8(1.4,2.8)$ \\
\hline
\end{tabular}

Definition of abbreviations: APACHE // Acute Physiology and Chronic Health Evaluation II, COPD chronic obstructive pulmonary disease, FiO2 fraction of inspired oxygen, IMV invasive mechanical ventilation, $\mathrm{PaCO} 2$ Partial pressure of carbon dioxide in arterial blood, $\mathrm{PaO} 2$ Partial pressure of oxygen in arterial blood, PEEP positive end-expiratory pressure, Ppeak peak airway pressure, VT tidal volume, $V T$ pbw predicted body weight of tidal volume

(Streptococcus pneumoniae), patient 2 was reintubated on the seventh day after extubation because of severe hypoxemia ( $\mathrm{SpO} 2$ 85\%) and respiratory distress (RR $38 \mathrm{bpm}$ ) even with maximal noninvasive positive pressure ventilation ( $\mathrm{S} / \mathrm{T}$ mode, $\mathrm{FiO} 2$ 1.0) and ECMO support. Patient 4 was removed from tracheal intubation after 29 days of ECMO treatment. As a result of the progressing of Staphylococcus aureus pneumonia accompanied by sever empyema and septic shock (BP 90/60 $\mathrm{mmHg}$, Lac $11.7 \mathrm{mmol} / \mathrm{L}$ ), HFNC (gas flow $50 \mathrm{~L} / \mathrm{min}, \mathrm{FiO} 2$ 0.6) was difficult to maintain oxygenation and to relieve dyspnea (RR 35 beats / $\mathrm{min}$ ) after 2 days of awake ECMO, endotracheal intubation was performed again. Patient 6 started awake ECMO after 7 days of ECMO treatment, and appeared severe hypoxemia ( $\mathrm{SpO} 2$ 88\%) and dyspnea (RR $30 \mathrm{bpm}$ ) even with NPPV support (continuous positive airway pressure $8 \mathrm{mmHg}$, FiO2 1.0) on the fifth day of awake ECMO. The patient was finally endotracheally intubated again due to the uncontrolled hospital acquired pneumonia. One patient (Patient 12) successfully underwent awake ECMO at the first time, but severe dyspnea (RR 36 bpm) occurred after removal of the ECMO catheters because of pulmonary embolism, subsequently died of hypovolemic shock and multiple organ failure even ECMO was introduced again.

The total duration of ECMO run in this cohort was $26.0(15.5,64.8)$ days. The maximum ECMO duration was 121 days with a single ECMO membrane when waiting native lung recovery, and the patient survived (Patient 5). The total invasive ventilation duration, lengths of stay in the ICU and hospital were 14.0(12.0, 37.3) days, $33.0(22.3,56.5)$ days and $46.5(27.3,84.8)$ days, respectively.

\section{Complications}

Pneumothorax (42\%, 5 cases) and VAP (33\%, 4 cases) were the main ventilator associated-complications before the use of awake ECMO in the cohort. The most common ECMO-associated complications included air in circuit $(8 \%, 1$ case), renal replacement therapy (8\%, 1case) and ECMO cannula infection (17\%, 2 cases), which also had occurred before the start of awake ECMO.

\section{Discussion}

In this retrospective analysis of 12 severe ARDS patients treated with prolonged ECMO, we mainly found that the implementation of awake ECMO in the late stage of ARDS could prompt native lung recovery and would be associated with higher hospital survival rate (66.7\%), compared with prior Extracorporeal Life Support Organization registry reported survival rate (45.4\%) of prolonged ECMO patients [24]; and awake ECMO did not increase the incidence of ECMO-related complications. It is worth noting that none of the patients with awake ECMO failure survived.

One of the main advantages of awake ECMO lies in the application of ECMO instead of IMV to avoid VAP. ECMO patients are susceptible to VAP due to severe illness, ECMO-induced immunosuppression and a high risk of intestinal microbial translocation [25]. Recently, Grasselli and colleagues [26] found that VAP is the most common type of ECMO-related nosocomial infection; its incidence is as high as $35 \%$ or 31.0 cases/1000 ECMO days, and it significantly increased mortality and prolonged the durations of mechanical ventilation, ICU stay and ECMO run. Recently, Rosenberg and colleagues reported that some severe ARDS patients may need more than 2-4 weeks before native lung recovery occurs [22], during which prolonged IMV will inevitably increase the risk of VAP. In our study, the incidence of VAP before awake ECMO was as high as $33 \%$, similar to that reported by Grasselli [26]. Furthermore, 6 (50\%) patients needed ECMO support for more than 4 weeks, and the longest duration of ECMO support was 121 days. Therefore, awake ECMO would facilitate early extubation [22] 

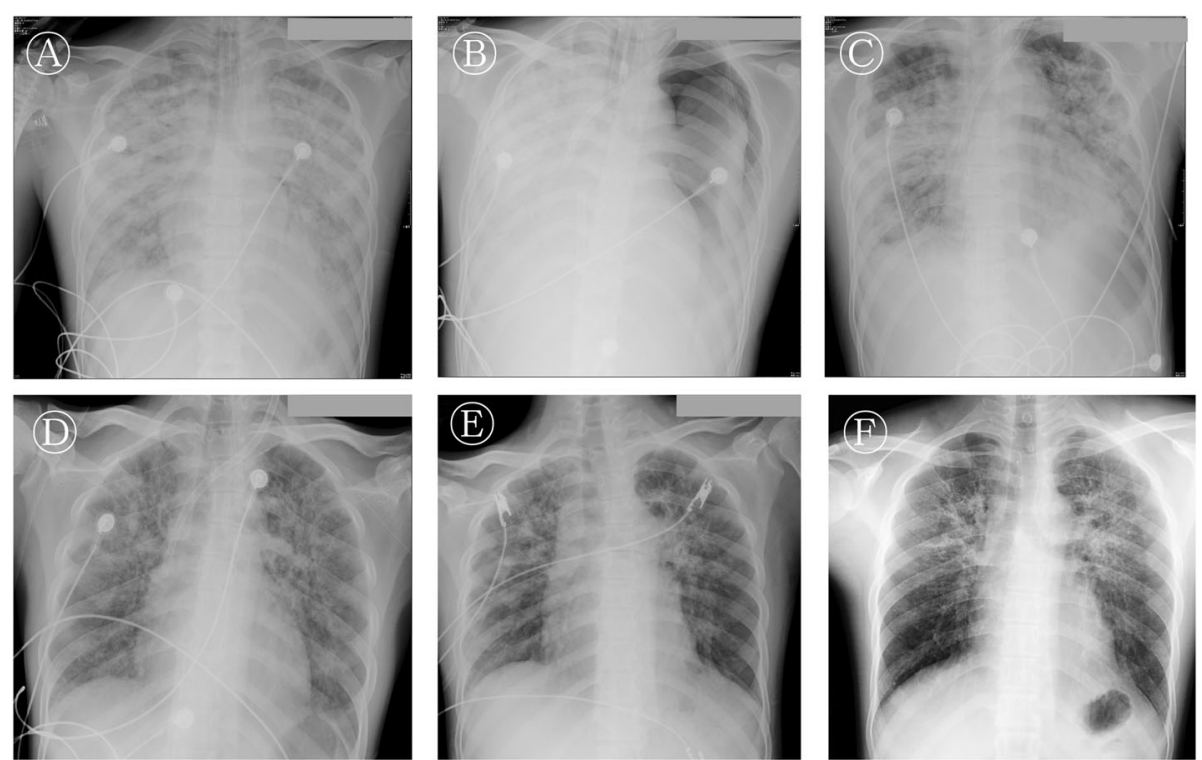

Fig. 1 A typical serial chest radiographs of awake ECMO patients (Patient 10). a: On ICU admission day. This is the initial chest radiograph after intubation. Increased bilateral opacity in both lungs are noted. $\mathbf{b}$ : The second day after ICU admission. ECMO insertion was done due to refractory hypoxemia. Chest $x$-ray shows progressive increase of right opacity and newly left pneumothorax. The left pneumothorax was improved with chest tube and lower mechanical ventilation support level due to ECMO. c: On ECMO 5 days. There is improved pulmonary infiltration and pneumothorax, the patient was extubated and underwent awake ECMO to avoid ventilator-associated pneumonia. d: On ECMO 30 days. The patient was weaned from ECMO after this chest x-ray. e: Fourteen days after weaning from ECMO and discharge. f: one month after discharge

and avoid the risk of VAP for severe ARDS patients requiring prolonged ECMO treatment.

Another important advantage of awake ECMO is the reduced need for sedative and analgesic drugs to facilitate early physical activity and rehabilitative exercise, which can decrease the risk of ICU-acquired weakness $[27,28]$. At our center, progressive physical exercises such as sitting on the bed, performing some activities on the bed, and getting out of bed are routinely carried out once awake ECMO is implemented with the help of intensivists, respiratory therapists, nurses and physical therapists, which may also be an important reason for the significant improvement in the prognosis of awake ECMO patients.

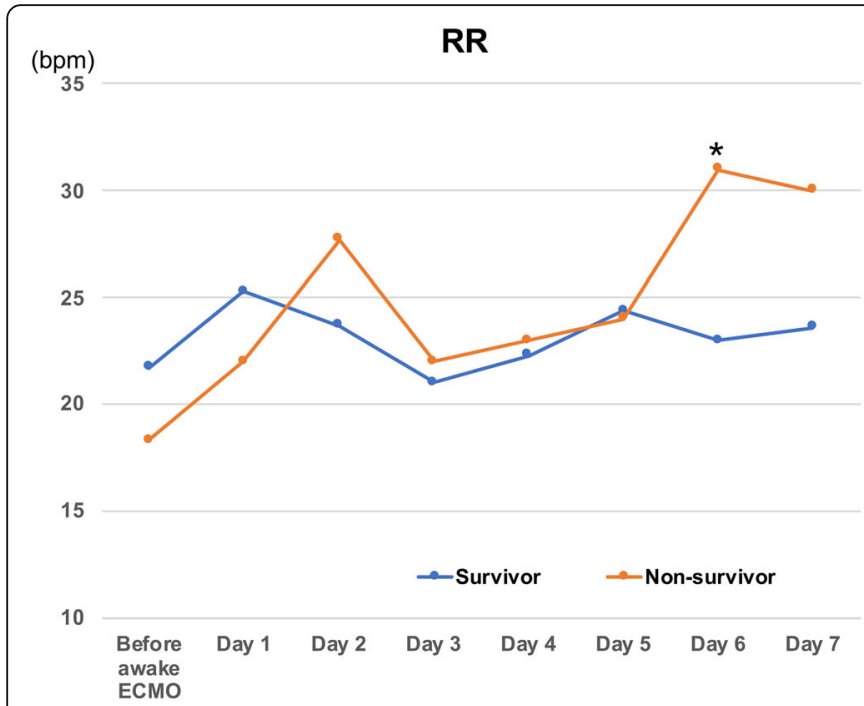

$\begin{array}{ll}(\mathrm{bpm}) & \text { HR } \\ 150 & \end{array}$

120

90

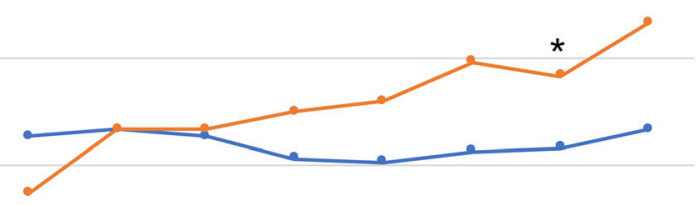

60

30

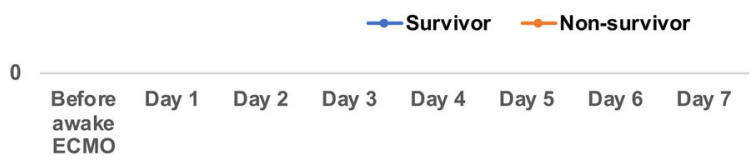

Fig. 2 The changes of respiratory rate (left chart) and heart rate (right chart) after extubation in awake ECMO patients. Blue lines represent the survivors with awake ECMO success, yellow lines represent the non-survivors with awake ECMO failure. ${ }^{*} P<0.05$ between survivor and non-survivor group 
Through chest computed tomographic scan, we know that in the late stage of ARDS, the lung tissue is characterized by lower respiratory compliance and high amounts of dead space and is more likely to develop bullae and pneumothorax [29]. Reducing the occurrence of lung injury and promoting lung repair are the focus of ventilation management during the late stage of ARDS $[29,30]$. Therefore, for late ARDS patients treated with ECMO, we speculate that when compared with the combination of ECMO and IMV, the early implementation of awake ECMO and extubation may further eliminate lung stress and strain of damaged lung tissue caused by invasive positive pressure ventilation (for example, $42 \%$ of awake ECMO patients appeared barotrauma before extubation). However, without invasive ventilatory support, the intensity of spontaneous breathing and transpulmonary pressure will increase, and lung injury in ARDS patients may be aggravated during awake ECMO $[1,8]$. Recently, Mauri and colleagues showed that respiratory drive and spontaneous breathing effort during the late stage of ARDS could be adjusted precisely by ECMO gas flow [21]. Therefore, before extubation and awake ECMO, it should be carefully evaluated whether ECMO alone could easily regulate the intensity of spontaneous breathing, and then weigh the risks of high shear stress from increased spontaneous breathing effort [31] after extubation against the risks of ongoing sedative and invasive positive pressure ventilation.

Although awake ECMO has evident above-mentioned clinical benefits, the indications and optimal timing of awake ECMO for severe ARDS remain unclear. Hannover Medical Center first reported the successful use of awake ECMO in the early stage of severe ARDS to avoid intubation in strictly selected patients in case reports [16, 17]. In addition, Yeo and colleagues [18] used awake ECMO as a weaning strategy in 10 patients with severe postoperative ARDS and found that $70 \%$ of the patients were successfully weaned from IMV and ECMO, the mean ECMO duration was only $9.1 \pm 2.2$ days. Be different from these researches, we tried to explore the clinical advantages of awake ECMO at the late stage of severe ARDS receiving prolonged ECMO treatment [median ECMO duration $26.0(15.5,64.8)]$. In the early stage of the disease, to attenuate lung injury and reduce venous admixture, positive pressure ventilation is often required to open the alveoli and keep them open. Additionally, most severe ARDS patients need artificial airways for sputum drainage, airway protection and infection control. In fact, control ventilation mode in the early stage of severe ARDS may be more important than assisted ventilation mode to improve clinical outcomes [32]. Therefore, we think that awake ECMO could be considered as soon as possible if severe ARDS patients treated with prolonged ECMO meet the following indications, especially in the case of patients with a high risk of barotrauma and VAP: the recovery of pneumonia; consciousness and good airway protection capacity; a moderate respiratory support level with airway peak pressure $<20 \mathrm{cmH} 2 \mathrm{O}, \mathrm{PEEP}<10 \mathrm{cmH} 2 \mathrm{O}$ and $\mathrm{FiO} 2<0.5$; ECMO blood flow $<4 \mathrm{~L} / \mathrm{min}$; satisfactory gas exchange; and no serious ECMO-related complications. Regarding the type of oxygen therapy during the awake ECMO strategy, high-flow nasal cannula may be the best choice. A recent study confirmed that high-flow nasal cannula can effectively prevent respiratory failure and reintubation after extubation in acute respiratory failure patients [33]. In this study, 67\% of the awake ECMO patients were supported by a combination of ECMO and highflow nasal cannula.

In addition to careful case selection, maintaining the ECMO run carefully and avoiding ECMO-related severe complications are also important prerequisites for the successful implementation of awake ECMO. There was no obvious increase in ECMO-related complications in our patients, which may be explained by the promising advancement of ECMO-related equipment and technology, such as low-resistance gas exchange membranes, centrifugal blood pumps, heparin-coated catheters and improved intravascular catheters, as well as advancements in the management of critical illness [2, 34].

This study has several limitations. First, the number of patients was small, and all patients were selected from a single center. Second, this study was not prospectively designed, and the possibility of patient selection and intervention biases cannot be excluded. Finally, awake ECMO was implemented after median 10.2 days of $\mathrm{ECMO}$, and the results of the study cannot indicate whether earlier implementation of awake ECMO would further improve the clinical outcomes; therefore, a prospective clinical study is required to explore the best timing of awake ECMO implementation during prolonged ECMO treatment.

\section{Conclusions}

Our data suggest that awake ECMO is a feasible and safe strategy for carefully selected pulmonary ARDS patients receiving prolonged ECMO support to wait for native lung recovery. Comparative analyses of awake ECMO and non-awake ECMO are required to prospectively investigate the optimal ECMO weaning strategy for prolonged ECMO patients.

\section{Abbreviations}

APACHE II: Acute Physiology and Chronic Health Evaluation II; ARDS: Acute respiratory distress syndrome; ECMO: Extracorporeal membrane oxygenation; IMV: Invasive mechanical ventilation; PEEP: Positive end expiratory pressure; VAP: Ventilator-associated pneumonia; VILI: Ventilator-induced lung injury; W-ECMO: Venovenous extracorporeal membrane oxygenation 


\section{Acknowledgments}

The authors thank all the medical and nursing staffs of our center.

\section{Authors' contributions}

J.X. and Q.Z. contributed to the design and conception of the study, data analysis and interpretation, and drafted the manuscript; S.G., M.L., D.L., X.H., L.Y. and L.W. contributed to data collection and interpretation, and revised the manuscript; G.F. contributed to statistical analysis and revised the manuscript. All authors read and approved the final version of the manuscript.

\section{Funding}

Supported by the National Key Research and Development Program of China (Grant NO. 2016YFC1304300), the National Natural Science Foundation of China (Grant NO. 81401629), National Natural Science Foundation of China (Grant NO. 81700083), CAMS Innovation Fund for Medical Sciences (2018I2M-1-003) and Non-profit Central Research Institute Fund of CAMS (2019TX320006)

\section{Availability of data and materials}

The data that support the findings of this study are available from the corresponding author upon reasonable request.

\section{Ethics approval and consent to participate}

This study was approved by the ethics committee of China-Japan Friendship Hospital (201711). Written informed consent was provided from each patient's next of kin as the patient was unable to make decisions because of a critically ill status and consciousness disturbance.

\section{Consent for publication}

Not applicable.

\section{Competing interests}

The authors declare no competing interests.

\section{Author details}

${ }^{1}$ National Clinical Research Center for Respiratory Diseases, Center for Respiratory Diseases, China-Japan Friendship Hospital, Beijing, China. ${ }^{2}$ Department of Pulmonary and Critical Care Medicine, China-Japan Friendship Hospital, Beijing, China. ${ }^{3}$ Capital Medical University, Beijing, China. ${ }^{4}$ Institute of Clinical Medical Sciences, China-Japan Friendship Hospital, Beijing, China.

Received: 16 December 2018 Accepted: 29 November 2019 Published online: 09 December 2019

\section{References}

1. Combes A, Pesenti A, Ranieri VM. Fifty years of research in ARDS. Is extracorporeal circulation the future of acute respiratory distress syndrome management? Am J Respir Crit Care Med. 2017;195:1161-70.

2. Riley JB, Scott PD, Schears GJ. Update on safety equipment for extracorporeal life support (ECLS) circuits. Semin Cardiothorac Vasc Anesth. 2009;13:138-45.

3. Davies A, Jones D, Bailey M, Beca J, Bellomo R, Blackwell N, Forrest P, Gattas D, Granger E, Herkes R, Jackson A, McGuinness S, Nair P, Pellegrino V, Pettila V, Plunkett B, Pye R, Torzillo P, Webb S, Wilson M, Ziegenfuss M. Extracorporeal membrane oxygenation for 2009 influenza a(H1N1) acute respiratory distress syndrome. JAMA. 2009:302:1888-95.

4. Karagiannidis C, Brodie D, Strassmann S, Stoelben E, Philipp A, Bein T, Muller T, Windisch W. Extracorporeal membrane oxygenation: evolving epidemiology and mortality. Intensive Care Med. 2016;42:889-96.

5. Schmidt M, Bailey M, Sheldrake J, Hodgson C, Aubron C, Rycus PT, Scheinkestel C, Cooper DJ, Brodie D, Pellegrino V, Combes A, Pilcher D. Predicting survival after extracorporeal membrane oxygenation for severe acute respiratory failure. The respiratory extracorporeal membrane oxygenation survival prediction (RESP) score. Am J Respir Crit Care Med. 2014;189:1374-82.

6. Roch A, Hraiech S, Masson E, Grisoli D, Forel JM, Boucekine M, Morera P, Guervilly C, Adda M, Dizier S, Toesca R, Collart F, Papazian L. Outcome of acute respiratory distress syndrome patients treated with extracorporeal membrane oxygenation and brought to a referral center. Intensive Care Med. 2014:40:74-83.

7. Brogan TV, Thiagarajan RR, Rycus PT, Bartlett RH, Bratton SL. Extracorporea membrane oxygenation in adults with severe respiratory failure: a multicenter database. Intensive Care Med. 2009;35:2105-14.

8. Langer T, Santini A, Bottino N, Crotti S, Batchinsky Al, Pesenti A, Gattinoni L. "Awake" extracorporeal membrane oxygenation (ECMO): pathophysiology, technical considerations, and clinical pioneering. Crit Care. 2016;20:150.

9. Fuehner T, Kuehn C, Hadem J, Wiesner O, Gottlieb J, Tudorache I, Olsson KM, Greer M, Sommer W, Welte T, Haverich A, Hoeper MM, Warnecke G. Extracorporeal membrane oxygenation in awake patients as bridge to lung transplantation. Am J Respir Crit Care Med. 2012;185:763-8.

10. Crotti S, lotti GA, Lissoni A, Belliato M, Zanierato M, Chierichetti M, Di Meo G, Meloni F, Pappalettera M, Nosotti M, Santambrogio L, Vigano M, Braschi A, Gattinoni L. Organ allocation waiting time during extracorporeal bridge to lung transplant affects outcomes. Chest. 2013;144:1018-25.

11. Nosotti M, Rosso L, Tosi D, Palleschi A, Mendogni P, Nataloni IF, Crotti S, Tarsia P. Extracorporeal membrane oxygenation with spontaneous breathing as a bridge to lung transplantation. Interact Cardiovasc Thorac Surg. 2013;16:55-9.

12. Biscotti M, Gannon WD, Agerstrand C, Abrams D, Sonett J, Brodie D, Bacchetta M. Awake extracorporeal membrane oxygenation as bridge to lung transplantation: a 9-year experience. Ann Thorac Surg. 2017;104:412-9.

13. Burki NK, Mani RK, Herth FJF, Schmidt W, Teschler H, Bonin F, Becker H, Randerath WJ, Stieglitz S, Hagmeyer L, Priegnitz C, Pfeifer M, Blaas SH, Putensen C, Theuerkauf N, Quintel M, Moerer O. A novel extracorporeal $\mathrm{CO}(2)$ removal system: results of a pilot study of hypercapnic respiratory failure in patients with COPD. Chest. 2013;143:678-86.

14. Del Sorbo L, Pisani L, Filippini C, Fanelli V, Fasano L, Terragni P, Dell'Amore A, Urbino R, Mascia L, Evangelista A, Antro C, D'Amato R, Sucre MJ, Simonetti U, Persico P, Nava S, Ranieri VM. Extracorporeal Co2 removal in hypercapnic patients at risk of noninvasive ventilation failure: a matched cohort study with historical control. Crit Care Med. 2015;43:120-7.

15. Kluge S, Braune SA, Engel M, Nierhaus A, Frings D, Ebelt H, Uhrig A, Metschke M, Wegscheider K, Suttorp N, Rousseau S. Avoiding invasive mechanical ventilation by extracorporeal carbon dioxide removal in patients failing noninvasive ventilation. Intensive Care Med. 2012;38:1632-9.

16. Hoeper MM, Wiesner $O$, Hadem J, Wahl O, Suhling $H$, Duesberg $C$, Sommer W, Warnecke G, Greer M, Boenisch O, Busch M, Kielstein JT, Schneider A Haverich A, Welte T, Kuhn C. Extracorporeal membrane oxygenation instead of invasive mechanical ventilation in patients with acute respiratory distress syndrome. Intensive Care Med. 2013;39:2056-7.

17. Wiesner O, Hadem J, Sommer W, Kuhn C, Welte T, Hoeper MM Extracorporeal membrane oxygenation in a nonintubated patient with acute respiratory distress syndrome. Eur Respir J. 2012:40:1296-8.

18. Yeo HJ, Cho WH, Kim D. Awake extracorporeal membrane oxygenation in patients with severe postoperative acute respiratory distress syndrome. J Thorac Dis. 2016;8:37-42

19. Langer T, Vecchi V, Belenkiy SM, Cannon JW, Chung KK, Cancio LC, Gattinoni L, Batchinsky Al. Extracorporeal gas exchange and spontaneous breathing for the treatment of acute respiratory distress syndrome: an alternative to mechanical ventilation?*. Crit Care Med. 2014;42:e211-20.

20. Crotti S, Bottino N, Ruggeri GM, Spinelli E, Tubiolo D, Lissoni A, Protti A, Gattinoni L. Spontaneous breathing during extracorporeal membrane oxygenation in acute respiratory failure. Anesthesiology. 2017;126:678-87.

21. Mauri T, Grasselli G, Suriano G, Eronia N, Spadaro S, Turrini C, Patroniti N, Bellani G. Pesenti A. Control of respiratory drive and effort in extracorporeal membrane oxygenation patients recovering from severe acute respiratory distress syndrome. Anesthesiology. 2016;125:159-67.

22. Rosenberg AA, Haft JW, Bartlett R, Iwashyna TJ, Huang SK, Lynch WR, Napolitano LM. Prolonged duration ECMO for ARDS: futility, native lung recovery, or transplantation? ASAIO J. 2013:59:642-50.

23. Camboni D, Philipp A, Lubnow M, Bein T, Haneya A, Diez C, Schmid C, Muller T. Support time-dependent outcome analysis for veno-venous extracorporeal membrane oxygenation. Eur J Cardiothorac Surg. 2011;40:1341-6.

24. Posluszny J, Rycus PT, Bartlett RH, Engoren M, Haft JW, Lynch WR, Park PK, Raghavendran K, Napolitano LM. Outcome of adult respiratory failure patients receiving prolonged (>/=14 days) ECMO. Ann Surg. 2016;263:573-81.

25. Biffi S, Di Bella S, Scaravilli V, Peri AM, Grasselli G, Alagna L, Pesenti A, Gori A. Infections during extracorporeal membrane oxygenation: epidemiology, risk factors, pathogenesis and prevention. Int J Antimicrob Agents. 2017;50:9-16. 
26. Grasselli G, Scaravilli V, Di Bella S, Biffi S, Bombino M, Patroniti N, Bisi L, Peri AM, Pesenti A, Gori A, Alagna L. Nosocomial infections during

extracorporeal membrane oxygenation: incidence, etiology, and impact on Patients' outcome. Crit Care Med. 2017:45:1726-33.

27. Ko Y, Cho YH, Park YH, Lee H, Suh GY, Yang JH, Park CM, Jeon K, Chung CR. Feasibility and safety of early physical therapy and active mobilization for patients on extracorporeal membrane oxygenation. ASAIO J. 2015;61:564-8.

28. Abrams $D$, Javidfar J, Farrand $E$, Mongero $L B$, Agerstrand $C L$, Ryan $P$,

Zemmel D, Galuskin K, Morrone TM, Boerem P, Bacchetta M, Brodie D. Early mobilization of patients receiving extracorporeal membrane oxygenation: a retrospective cohort study. Crit Care. 2014;18:R38.

29. Gattinoni L, Bombino M, Pelosi P, Lissoni A, Pesenti A, Fumagalli R, Tagliabue M. Lung structure and function in different stages of severe adult respiratory distress syndrome. JAMA. 1994;271:1772-9.

30. Hudson LD, Hough CL. Therapy for late-phase acute respiratory distress syndrome. Clin Chest Med. 2006;27:671-7.

31. Brochard L, Slutsky A, Pesenti A. Mechanical ventilation to minimize progression of lung injury in acute respiratory failure. Am J Respir Crit Care Med. 2017;195:438-42.

32. Papazian L, Forel JM, Gacouin A, Penot-Ragon C, Perrin G, Loundou A, Jaber S, Arnal JM, Perez D, Seghboyan JM, Constantin JM, Courant P, Lefrant JY, Guerin C, Prat G, Morange S, Roch A. Neuromuscular blockers in early acute respiratory distress syndrome. N Engl J Med. 2010;363:1107-16.

33. Maggiore SM, Idone FA, Vaschetto R, Festa R, Cataldo A, Antonicelli F, Montini L, De Gaetano A, Navalesi P, Antonelli M. Nasal high-flow versus Venturi mask oxygen therapy after extubation. Effects on oxygenation, comfort, and clinical outcome. Am J Respir Crit Care Med. 2014;190:282-8.

34. Kon ZN, Dahi S, Evans CF, Byrnes KA, Bittle GJ, Wehman B, Rector RP, McCormick BM, Herr DL, Sanchez PG, Pham SM, Griffith BP. Long-term Venovenous extracorporeal membrane oxygenation support for acute respiratory distress syndrome. Ann Thorac Surg. 2015;100:2059-63.

\section{Publisher's Note}

Springer Nature remains neutral with regard to jurisdictional claims in published maps and institutional affiliations.

Ready to submit your research? Choose BMC and benefit from:

- fast, convenient online submission

- thorough peer review by experienced researchers in your field

- rapid publication on acceptance

- support for research data, including large and complex data types

- gold Open Access which fosters wider collaboration and increased citations

- maximum visibility for your research: over $100 \mathrm{M}$ website views per year

At $\mathrm{BMC}$, research is always in progress.

Learn more biomedcentral.com/submissions 